\title{
Coesão e interesses da medicina paulista diante do populismo adhemarista: contradições e ambivalências
}

\author{
Fábio de Oliveira Almeida \\ Mestre em Sociologia (Universidade Federal de São Carlos) \\ fabioliveira@yahoo.com.br
}

\begin{abstract}
Resumo Este artigo trata das relações entre o processo de profissionalização dos médicos paulistas e o fenômeno do adhemarismo. Como governador, Adhemar de Barros empreendeu políticas de saúde que interferiram no processo de profissionalização dessa carreira em São Paulo. Avaliamos como essa profissão relacionou-se com o Estado adhemarista, destacando os interesses político-profissionais e as ações associativas de aproximação-distanciamento entre médicos e governo. Nosso foco dirigiu-se para seu segundo governo (1947-1951), quando se verificou o movimento de Assembléia Permanente de Médicos e Engenheiros, em que estes procuraram obter a equiparação econômico-jurídica, como carreiras públicas, junto aos advogados, numa ação que revelou as contradições e ambivalências entre profissionalismo e política, bem como a coesão associativa dos médicos e como as fronteiras entre profissionalismo e política não estavam bem demarcadas entre tais médicos.
\end{abstract}

Palavras-chave: medicina em São Paulo, adhemarismo, profissionalismo e política; interesses profissionais.

\begin{abstract}
A NTes de Desenvolver sua carreira política, Adhemar de Barros formou-se e atuou como médico em São Paulo, o que não impediu que seu segundo governo experimentasse conflitos com os médicos paulistas. Neste governo populista (1947-1951), percebemos que estes médicos experimentaram uma particular situação referente às condições profissionais sob as quais se achavam junto ao governo, particularmente se comparados a outros grupos que o integravam. Mas se os médicos paulistas reconheciam essa fonte de fragilidade, eles também vivenciaram um processo de fortalecimento, mobilizando-se pela equiparação da categoria ao grupo de advogados servidores estaduais, que possuíam uma posição relativamente superior.

Tal processo de coesão e fortalecimento de uma identidade coletiva estadual acompanhou o processo de interiorização das estruturas de saúde estaduais. Neste período, verificamos a criação de uma Secretaria de Saúde Pública, a expansão de diversos centros/postos sanitários e a instituição das Delegacias Regionais de Saúde. Acreditamos que tais mudanças, com a interiorização de serviços e estruturas político-administrativas, representaram um importante fator para impulsionar o processo de organização associativa dos médicos paulistas em nível estadual, contextualizando as relações entre adhemarismo e profissionalismo médico.
\end{abstract}


A política profissional deve conviver com a política convencional ou partidária em alguma medida e em determinados termos. Entretanto, essa convivência nem sempre é harmoniosa, sendo permeada de contradições e ambivalências. Entre os médicos paulistas, essa situação expressou-se em um movimento variável de aproximação-distanciamento do ponto de vista de suas ações junto ao Estado e da convivência de interesses e sinais ideológicos opostos e ambivalentes. Neste artigo, enfocaremos as ações e interesses médicos em relação ao Estado adhemarista em torno da questão de equiparação.

Essa dinâmica iniciou-se antes e se estendeu por todo este governo. Em parte, por conta de particularidades da ação do populismo adhemarista, que, quanto à relação política convencional-profissionalismo, não seguiu uma trajetória uniforme. French (1995) propõe que as relações entre Estado e sociedade nos governos populistas (1930-1964) aconteciam na base de contraditórias relações de aliança, que, embora estabelecidas entre atores desiguais em termos sociopolíticos, não prescindiam de negociações e reciprocidades. Investigamos aqui as relações de alianças entre médicos paulistas e adhemarismo. No sistema de alianças adhemaristas, não faltaram acordos e rupturas, aceitação de interesses mútuos e recusas. Não por acaso, Duarte (2002) definiu a figura política de Adhemar de Barros como essencialmente ambígua. Assim, percebemos uma das bases que caracterizaram as relações de aproximação-distanciamento entre adhemarismo e medicina paulista.

Freidson $(2001)^{1}$ desenvolveu um valioso modelo típico-ideal de análise a respeito das profissões, como a medicina. Segundo o autor, existiriam três princípios organizadores das relações formais de trabalho: o de livre-mercado, o burocrático racional-legal e o ocupacional/ profissional. Cada um concorreria com os demais no sentido da organização do trabalho, e embora nenhum destes se estabelecesse de forma absoluta, toda divisão de trabalho seria dominada por algum dos mesmos, sendo acompanhados por ideologias específicas.

O conteúdo ideológico fundamental da lógica de mercado seria a defesa da livre escolha de consumidores existentes no mercado, sendo combatidos os monopólios profissionais baseados na exigência de diploma de Nível Superior para o exercício de uma ocupação: consumismo e competição condensam os valores básicos desta lógica. Na lógica burocrática, por seu turno, defende-se o controle e a eficiência de corpos administrativos de empresas públicas ou privadas sobre a dinâmica de trabalho, sendo as profissões vistas como corporações que, protegidas pelo discurso do ideal de serviço, lutam em prol de interesses específicos. Já a ideologia que acompanharia o princípio ocupacional seria a do profissionalismo, susten- tada no mérito profissional e na expertise, alegando que os profissionais atuam de maneira autônoma, tanto da clientela, como dos patrões, na defesa de valores transcendentes, como a 'saúde' pela medicina.

$\mathrm{O}$ autor entende que profissionalismo seria não apenas uma ideologia, mas também um conceito típico-ideal que reuniria as características institucionais e ideológicas dos grupos ocupacionais sob a lógica profissional, sendo cinco as características desse conceito. Delinearemos abaixo tais características em análise das condições da medicina paulista, que se encontrava organizada conforme o princípio profissional neste governo adhemarista.

A medicina representava um tipo de trabalho especializado da economia formal, que já nos anos 1940 possuía em São Paulo uma base teórica de caráter discricionário (expertise), e que ocupava um espaço de destaque na força de trabalho do Estado: atestam esta assertiva diversas especialidades médicas existentes em São Paulo entre 1940-1950, como: clínica geral, pediatria, neuropsiquiatria, ginecologia/obstetrícia, dermatologia e saúde pública. Estas especialidades possuíam conceitos e técnicas para seus profissionais realizarem diagnósticos, tratamentos e/ou orientações terapêuticas junto a representativos segmentos sociais.

Estes médicos controlavam uma 'jurisdição exclusiva' e, em relação a outros profissionais, ocupavam posição dominante nos hospitais, serviços sanitários e na área de saúde em geral. Possuíam credenciais garantidoras do exercício profissional exclusivo e instituições de formação de nível superior, situadas fora do mercado de trabalho, sendo que existiam pelo menos três grandes instituições de credenciamento em São Paulo que transmitiam aos estudantes conhecimentos médicos especializados: Faculdade de Medicina da USP, Faculdade de Higiene e Saúde Pública e Escola Paulista de Medicina.

Enfim, encontramos nesse grupo uma ideologia que priorizava o compromisso com a realização de um bom trabalho em vez da eficiência econômica da atividade: notável em suas críticas à influência negativa de controles sobre seu trabalho oferecidos pela iniciativa privada, que visaria mais o lucro do que a oferta de serviços com qualidade, ou por serviços estatais, os quais não ofereciam, segundo os médicos, condições adequadas ao seu trabalho e não atendiam às reais demandas de assistência à população. Apesar de críticas à atuação estatal, o comprometimento com valores distantes de interesses setoriais também se expressava na defesa da participação mais extensa do Estado na área de saúde, a despeito de temores sobre o consequente assalariamento de profissionais (Ramos, 1949).

Encontramos, assim, linhas de aproximação entre as características típico-ideais do profissionalismo e elementos peculiares à medicina paulista, pois esta controlava uma área exclusiva de atuação profissional e 
trabalhava com considerável autonomia técnica. Acreditamos que, nesta situação, os médicos estiveram em condições de manter uma relação de interlocução com as estruturas estatais adhemaristas.

Freidson entende que variações institucionais e ideológicas no tipo de Estado, assim como de associações profissionais, funcionam como condicionantes que interagem com o tipo ideal do profissionalismo e matizam sua concretização empírica, interferindo nos processos de profissionalização rumo à autonomia ocupacional, sendo o Estado o condicionante mais significativo. Para o autor, as associações não são essenciais para a criação de uma profissão, mas podem ser influentes para os rumos do profissionalismo já estabelecido. Autonomia possuiria "[...] duas implicações bem diferentes - autonomia 'da' influência ou poder de outros, e autonomia para influenciar ou exercer poder sobre outros" (Freidson, 2009, p. 410).

Halliday (1999) sustenta que, acerca do Estado, os profissionais agiriam não apenas como fornecedores de expertise a este, mas, embasados na neutralidade do saber, organizar-se-iam em nome da sociedade para defendê-la da autoridade estatal, em favor do bem comum: seja por convicções políticas de esquerda ou em defesa de direitos civis, entre outros. Halliday não exclui a existência de interesses jurisdicionais na atuação profissional, nem interesses por status ou benefícios econômico-políticos. $\mathrm{O}$ autor entende que as motivações do agir profissional constituem um complexo amalgama de orientações, que difere conforme o contexto político, econômico ou profissional. Mas, ao lado dessas motivações, Halliday encontra uma motivação cívica, que denomina profissionalismo cívico: uma forma de agir com a qual as profissões fariam a sua própria política, centrada na neutralidade do saber e a partir de um mandato da sociedade civil, distinguindo-se da política convencional e se protegendo de seus custos para os grupos profissionais.

Halliday percebe uma tensa, mas necessária, coexistência entre o que chama de centro da profissão (formado pela elite, com perfil mais conservador) e a periferia (ou base, mais 'progressista'). O primeiro grupo estabelece uma fronteira mais rígida entre o aspecto técnico-profissional e o político (em sentido convencional ou partidário); já o segundo estabelece fronteiras menos nítidas, pois lida com causas politicamente substantivas, o que tende a fazer com que esses profissionais mesclem o aspecto técnico com interesses setoriais e partidários. Os dois polos seriam igualmente necessários para a preservação da posição social dos profissionais, contrabalançando elementos que preservam a autonomia (primeiro caso) e, por outro lado, a abertura aos clamores sociais por ações socialmente substantivas. Tal equilíbrio só permite a preservação da condição social da profissão se o centro mantiver predominantemente aquela separação entre política e profissão, e se o outro grupo se mantiver na periferia, de modo a evitar uma contaminação perigosa da profissão pela política convencional.
Essa polaridade permite uma aproximação da teoria de Halliday com a teoria do espaço social desenvolvida por Bourdieu a partir do conceito de campo. "O campo se define como o locus onde se trava uma luta concorrencial entre os atores em torno de interesses específicos que caracterizam a área em questão" (Ortiz, 1983, p. 19), e representaria um espaço em que se notam relações de poder em função da distribuição desigual de um quantum social que estabelece a posição de um agente específico em seu interior. Esse quantum o autor chama de capital social, sendo a estrutura do campo apreendida tomando-se como eixo fundamental os polos opostos dos dominantes e dos dominados. No primeiro grupo, situam-se os que possuem um máximo de capital social; já os dominados notabilizam-se pela ausência/raridade do mesmo. A divisão dominantes/dominados implica uma distinção entre ortodoxia e heterodoxia: o grupo dominante estabelece práticas ortodoxas de conservação do capital acumulado, ao passo que os dominados utilizam práticas sociais heterodoxas, a fim de desacreditar os detentores reais de capital legítimo.

No campo profissional médico, a conquista e manutenção da autonomia ocupacional é, segundo Freidson, a base de seu poder. Conforme Halliday, parte importante da conquista/manutenção dessa autonomia advém da preservação da neutralidade técnica diante dos custos da política convencional - estratégia comum aos membros da elite de uma profissão. Isso constitui uma espécie de ortodoxia, à qual se contrapõe uma heterodoxia, representada pela postura que aproxima o conhecimento técnico de ações políticas substantivas. No caso dos médicos paulistas, discutimos como lidaram com os custos relacionados às políticas adhemaristas de saúde, de modo que acompanhamos o movimento médico em busca de equiparação econômico-jurídica ante os advogados que igualmente trabalhavam para o governo. Tal questão implicou um contexto político-profissional com significativo impacto sobre a condição ocupacional médica.

Mas se a medicina paulista pode ser investigada como um campo de lutas entre grupos que divergem entre si quanto à sua relação com a política convencional, também é verdade que pode ser vista como um campo de lutas entre grupos que, neste governo, encontravam-se em lados distintos, com perfis profissionais diferenciados: médicos liberais e médicos especialistas que atuavam em equipes de saúde - seja em organizações privadas, seja em públicas.

Cada perfil estabelece diferente relação com pacientes, distinta forma de inserção no mercado de trabalho e peculiar maneira de relacionar-se com a área de saúde. Entre os liberais, encontramos tanto o generalista como o especialista. Os generalistas realizam trabalhos de assistência médica junto a pacientes em geral individualizados, atuam no mercado privado e se dedicam especialmente à medicina curativa. Especialistas que atuam no mercado privado são liberais ou se empregam em organizações, onde o trabalho médico é realizado 
em equipes de especialistas, operando principalmente em medicina curativa. Por sua vez, sanitaristas e outros médicos ligados ao Estado atuam como servidores públicos. Os sanitaristas realizam trabalhos de medicina coletiva, dedicando-se ao cuidado de enfermidades que afetam coletividades (endemias ou epidemias), e realizam a chamada medicina preventiva - embora, no Brasil, a saúde pública tenha combinado medicina preventiva e curativa ${ }^{2}$. Outros médicos servidores públicos realizam trabalhos de assistência médica em organismos estatais de assistência, como os institutos previdenciários de aposentadorias e pensões daquela época.

Analisamos uma configuração particular da medicina paulista, em que tais diferenças encontravam-se politicamente relativizadas ante o contexto de conflito entre o governo Adhemar e os médicos em torno da questão de equiparação. Portanto, essa caracterização do campo médico paulista com posições relativamente opostas não exclui as relações de aproximação e aliança entre os diferentes segmentos, com ações, interesses e posicionamentos ideológicos podendo convergir ou não, mais ou menos, conforme o contexto. Assim, podemos entender os fundamentos do maior nível de coesão entre os médicos de São Paulo no movimento político profissional estudado, servindo como a outra base das relações de aproximação-distanciamento entre adhemarismo e médicos. Evidenciaremos, ainda, como tais alianças estenderam-se às relações dos médicos com os engenheiros, que também se envolveram na questão de equiparação, expressando conexões da medicina com outros segmentos profissionais paulistas.

\section{Os processos de aproximação e distanciamento}

As aproximações entre médicos paulistas e adhemarismo aconteceram desde a busca de financiamento estadual para a construção da nova sede da Associação Paulista de Medicina (APM), que assim poderia ser centralizada em um único prédio, passando para as aproximações envolvendo a questão da assistência aos médicos, acertada entre o governo e a APM. Esta constituía a principal entidade médica paulista no pós-1930, tendo vivenciado mudanças estatutárias em 1948 que a tornaram efetivamente representativa dos médicos do Estado, estando presente em todos os momentos de aproximação-distanciamento. No polo oposto, a alternância aproximação-distanciamento levou ao desgaste das relações entre médicos e governo, fruto das tensões entre ambos os lados em torno da Assembléia Permanente de Médicos e Engenheiros, em que estes se alia- ram pela equiparação de vencimentos ante os advogados servidores públicos estaduais.

O caso da construção da nova sede da APM implicou negociações entre esta e o governo paulista, iniciadas com o trabalho do dirigente da APM Oscar Monteiro de Barros, que lutou pela obtenção de subvenção junto ao governo interventorista, quantia paga em parcelas até fins de 1945. Na gestão seguinte, o professor Jairo Ramos conseguiu outra subvenção estadual. Esta foi negociada com o Banco do Estado de São Paulo mediante nota promissória emitida pela APM. O pagamento dessa nota só aconteceu em novembro de 1946.

Enquanto se processava o recebimento dessa subvenção, a APM punha em marcha seu plano. Ainda em 1945, iniciaram-se negociações quanto ao terreno para a sede da entidade, concluídas em 1946. A entidade buscou fundos para a desejada construção, conquistados em janeiro de 1948 a partir de um empréstimo bancário da Caixa Econômica Federal. Esta concluiu que o montante seria entregue em parcelas conforme o andamento das obras. Assim, em 21 de fevereiro de 1948, lançou-se a pedra fundamental de construção, tendo esta sido concluída e inaugurada em janeiro de 1951.

Adhemar de Barros assumiu o poder estadual com uma espécie de crédito do governo estadual ante os médicos paulistas, que haviam recebido dessa instância o montante para a compra do terreno onde pretendiam construir sua sede. No entanto, esse crédito logo foi gasto em função da questão de equiparação. Mas, se a construção da nova sede surgiu antes do início de seu governo e se o acompanhou por um bom tempo, a questão da assistência aos médicos com recursos estaduais foi uma medida com desdobramentos que consideramos igualmente importantes, já que atendia a um aspecto que os sensibilizavam.

Adhemar de Barros sancionou, em janeiro de 1950, a Lei n. 610, que criou um serviço de assistência aos médicos paulistas. Este serviço surgiu a fim de prestar auxílio aos médicos que, exercendo seu trabalho no Estado, se encontrassem inválidos, enfermos ou em penúria. Tal assistência se estenderia às famílias de médicos falecidos sem recursos. Criou-se um fundo especial destinado à construção da Casa dos Médicos, responsável por cuidar de médicos em dificuldades. Foi estabelecida uma "taxa de assistência aos médicos", cobrada a partir de um selo adesivo denominado "Assistência aos Médicos", o qual deveria ser colado nos atestados de saúde. Para a execução do serviço, a lei designou o Departamento de Previdência da APM, entregando-lhe, mensalmente, o produto arrecadado por aquela taxa (Serviço de Assistência aos Médicos, 1950, p. 120-121).

Esse modelo de assistência prestigiou a APM diante de importantes círculos políticos, pois foi criado por meio de lei sancionada pelo governador, mas aprovada 
e decretada pela Assembléia Legislativa. Isso significou que o governo estava aberto às demandas dos médicos paulistas. No entanto, tal medida foi tomada apenas no último ano de governo, o que, quanto ao realizado anteriormente, significou uma mudança radical na postura do Executivo ante os médicos. Antes desse momento final de aproximação, houve um período de conflitos por conta da questão de equiparação.

Desde o início deste governo, existiram movimentações pela campanha de equiparação. Já em julho de 1947, essa questão entra nos debates da Assembléia Legislativa Estadual por meio de um pronunciamento do deputado Milton Caires de Brito, que fez a leitura de um memorial ao governador, preparado por médicos, no qual foram feitas referências à Constituição, que determinava maior remuneração e melhores condições de trabalho para diversas carreiras públicas. Nessa época, havia uma diferença salarial entre advogados e médicos, a favor dos primeiros. Diante disso, o deputado comunista declarou total apoio à reivindicação e fez um apelo aos colegas parlamentares para que se sensibilizassem em favor da medida (na Assembléia Legislativa Estadual, 1947). Este talvez tenha sido o primeiro passo com impacto político maior de um esforço para tornar esta reivindicação de conhecimento público e com força política.

Parece-nos que os médicos não conseguiram mobilizar os deputados constituintes estaduais, em 1947, no sentido de garantir a posição que os advogados conseguiram. A crítica médica dirigiu-se, inicialmente, para o Decreto-lei n. 17.330, de julho de 1947, que estabeleceu, para advogados na função pública, vencimentos superiores aos dos médicos. Tal condição foi reafirmada com a promulgação da Constituição Estadual de São Paulo de 1947. Conforme carta de outubro de 1948 dirigida ao governador Adhemar, do líder médico Dr. Alípio Correa Neto, desde o ano de 1947 o governador havia prometido cuidar do caso e havia se mostrado favorável a atender suas reivindicações. Ao mesmo tempo, contudo, ele se mostrou reticente em cumprir com o que prometera.

Em discurso em sessão de posse da nova diretoria da Sociedade de Medicina e Cirurgia de São Paulo, em março de 1948, o Dr. Alipio Correa Neto - que então passava a direção da entidade - sustentou que a Constituição Estadual havia operado uma distinção entre certas carreiras públicas, em detrimento de seus colegas. O médico enfatizou a necessidade destes se unirem em torno da equiparação e que, dessa forma, as entidades médicas também deveriam se aproximar, reforçando o movimento.

Ao que parece, os apelos do líder médico encontraram o apoio vislumbrado. Ainda em abril de 1948, iniciou-se um movimento médico reivindicatório em favor da equiparação econômico-jurídica ante os advogados do Departamento Jurídico do Estado de São Paulo. Organizado a partir de uma comissão central liderada pelo Dr. Alípio, o movimento de Assembléia Permanen- te mobilizou os profissionais da área. Além de comissão central presente na capital paulista, foram criadas outras 13 comissões em diferentes cidades do interior. Logo este movimento logrou o apoio de diversas entidades médicas e de boa parte dos profissionais.

Com pouco mais de trinta dias, o movimento já havia conseguido, aparentemente, sensibilizar o governo, a ponto de ter obtido uma audiência com o governador em que este acertou as seguintes medidas: comprometeu-se a incluir, no exercício orçamentário de 1949, a reestruturação da carreira médica equiparando-a a de advogados; autorizou que uma comissão de médicos poderia acompanhar a elaboração orçamentária para o mesmo ano, juntamente com o diretor do Serviço Civil. Diante disso, os médicos convidaram o governador a participar de uma das reuniões semanais da Assembléia Permanente (Médicos do Estado, 1948).

Em dezembro, os profissionais compuseram nova delegação a fim de tratar com o governador e obtiveram mais uma audiência; o mesmo novamente se comprometeu a trabalhar para atender as reivindicações. Tudo indicava que os médicos conseguiriam o atendimento de suas demandas, evidenciando que talvez predominasse o polo da aproximação entre o governo e os médicos. No entanto, essas medidas não tiveram continuidade, o que veio a fragilizar as relações entre as partes.

Em reunião com médicos da Assembléia Permanente, em maio de 1948, o Dr. Alipio comunicou que havia comparecido à Assembléia dos Engenheiros, “[...] em que ficou demonstrado que médicos e engenheiros pleiteavam idênticas reivindicações. Deliberou-se, então, a composição de uma Comissão Mista, [...] a fim de agir conjuntamente" (Médicos do Estado, 1948, p. 9). Afora uma direção política, havia também uma tesouraria que cuidava das finanças do movimento. Este sobreviveu, inicialmente, de doações de colegas da Engenharia e da Medicina. Contudo, a partir de julho de 1949, a tesouraria criou uma contribuição no valor de cem cruzeiros, que passou a ser cobrada dos profissionais envolvidos.

Já em junho de 1948, aprovou-se uma moção ao governador que demandava a indicação de um técnico para comandar a Secretaria de Saúde Pública. Os médicos almejavam a presença de um verdadeiro profissional da área, escolhido por critério técnico para comandar a secretaria. A reivindicação se relacionava à constante troca de secretários e pelo fato de que, por diversas vezes, o nome escolhido ter sido apenas o de um aliado político, que nem sempre tinha relações efetivas com a saúde, atrapalhando não apenas o andamento das atividades como contrariando um aspecto importante citado anteriormente acerca do profissionalismo médico, que via o âmbito de sua atuação profissional muito afetada pelo elevado nível de politização da saúde. Mas, afora esta demanda, os profissionais da Assembléia Permanente decidiram enviar uma mensagem de solidariedade aos colegas da Prefeitura de São Paulo, pois se encontravam igualmente em busca de reestruturação de carreira em 
âmbito municipal. Como vimos, os profissionais estabeleceram um plano de ação que deveria instalar progressivamente bases do movimento em importantes núcleos interioranos, de modo que decidiram fazer-se representar na inauguração da Assembléia Permanente de Médicos e Engenheiros da cidade de Santos. Além desta, Sorocaba e Ribeirão Preto também organizaram suas respectivas assembleias por essa época, estabelecendo um contato muito próximo com o centro do movimento em São Paulo.

Durante todo o processo, a comissão dirigente do movimento recebeu inúmeros telegramas de médicos, tanto da capital, como do interior, confirmando o apoio e participação dos mesmos e evidenciando a elevação do nível de coesão da categoria em torno desta causa. As mensagens vinham de importantes centros interioranos e expressavam a adesão, cada vez maior, de médicos de todo o Estado, tais como de: Santos, Sorocaba, Araras, Jaú, Marília, Franca, São José do Rio Preto, Catanduva, Ribeirão Preto, entre outras cidades paulistas.

Neste ritmo, em agosto de 1948, os profissionais iniciaram os preparativos para a Convenção Estadual de Médicos e Engenheiros de São Paulo. Este evento realizou-se em setembro de 1948 e, entre os participantes médicos, contou com a presença de Adhemar de Barros. Mais uma vez, este se comprometeu a atender as demandas de médicos e engenheiros.

Depois do evento, houve a apresentação de uma carta do líder da Assembléia Permanente, Dr. Alipio Correa Neto, em que o mesmo fez menção a uma nota taquigráfica da Convenção Estadual. Nesta, poder-se-ia extrair um pronunciamento do governador, que, presente ao evento, dirigiu-se aos médicos em campanha pela equiparação. Adhemar de Barros teria afirmado que se comprometia a enviar, num prazo de até trinta dias, um projeto de reajustamento de vencimentos de médicos para o exercício orçamentário de 1949.

Esse pronunciamento foi utilizado pelo Dr. Alipio em entrevista à imprensa. Contudo, em contato com a imprensa, Adhemar contestou seu próprio pronunciamento, afirmando não ter estipulado prazos para o cumprimento da demanda. Em resposta, o líder médico resolveu publicar a referida nota taquigráfica em que desmente a declaração anterior do governador. Com a publicação dessa nota, o Dr. Alipio acrescentou mais uma página às relações de aproximação-distanciamento, com trocas de acusações mútuas, inclusive de mentiras. Àquela altura, o presidente da APM, Dr. Jairo Ramos, tomou parte nas discussões e declarou à imprensa que protestava contra as afirmações de Adhemar, entendendo serem justas as demandas dos profissionais.

O movimento já havia conquistado o apoio de diversas entidades médicas e de engenheiros, entre as quais: o Centro Acadêmico Oswaldo Cruz - da Faculdade de Medicina da USP, o Centro de Estudos do Serviço de Tuberculose, a Sociedade Médica de Sorocaba, a Sociedade de Medicina e Cirurgia de São Paulo, o Sindicato
Médico de Campinas, a Sociedade Paulista de Medicina e Higiene Escolar, a Sociedade de Medicina Social e do Trabalho, a Sociedade de Oftalmologia de São Paulo, o Centro de Estudos Franco da Rocha, as associações de médicos e engenheiros de Santos, o Instituto de Engenharia, e ainda, Associação dos Engenheiros do Estado, o Sindicato Médico do Estado de São Paulo e a já mencionada Associação Paulista de Medicina. Aliás, no correr dos trabalhos, haveria a confirmação do apoio de entidades médicas de outros Estados, como a Associação Médica de Minas Gerais e a Academia Nacional de Medicina.

Embora toda essa mobilização, o movimento percebeu que as resistências do governo paulistas e a impostura no cumprimento de acordos exigiam atitudes mais firmes de sua parte. No mês de outubro de 1948, os profissionais decidem criar um fato com significado simbólico-político mais explícito quanto ao seu descontentamento. Em resolução aprovada nesse mês, decidiram junto de suas entidades profissionais que fechariam, em protesto, suas sedes por três dias (Médicos e Engenheiros, 1948). Como ao final do mês seguinte já não havia tempo hábil para que a medida de equiparação se incorporasse pelo Executivo à proposta orçamentária do ano seguinte, médicos e engenheiros mudam de tática e passam a buscar o apoio da Assembléia Legislativa. Com base nos pareceres favoráveis de dois juristas contatados, o professor Vicente Rao e o constitucionalista Carlos Maximiliano encontraram uma brecha legal para pedir a equiparação por meio da ação dos deputados estaduais. A nova tática foi proposta e votada pela Assembléia Permanente, sendo aprovada junto de um requerimento, segundo o qual, a comissão diretiva da Assembléia Permanente deveria entrar em contato imediatamente com o presidente da Assembléia Legislativa, entregando-lhe o texto do projeto e os aludidos pareceres para discussão.

Nessa mesma sessão, participou o presidente da APM, Dr. Jairo Ramos, que usou da palavra e declarou que, em reunião com seus associados, haviam decidido que: consideravam nula a palavra do governador, visto este ter prometido a equiparação, mas, igualmente, não ter cumprido a palavra; a APM passaria a considerá-lo inimigo da classe médica e poderia cassar-lhe o título de sócio benemérito concedido quando era interventor do Estado; oficiar dando conhecimento desse ato a todas as entidades médicas do país; exigir de todos os médicos que ocupavam cargos de confiança na administração estadual que, em 48 horas, decidissem se estavam ao lado do governador ou da classe; decorrido esse prazo, publicariam nos jornais os nomes dos médicos que pertenciam à classe e os que não mais; oficiar ao presidente executivo do VII Congresso Brasileiro de Higiene, que se realizaria em dezembro, que a APM não compareceria ao evento caso o governador dele participasse. Ao final da reunião, médicos e engenheiros discutiram possibilidades de tomar medidas mais duras para a conquista de seu objetivo. Em meio às discussões, emergiu a possibili- 
dade de a Assembléia Permanente estabelecer uma ação mais radical, isto é, um movimento grevista. A 21 de dezembro de 1948, os profissionais mobilizados decidiram entrar em greve por um dia. Cansados das reticências do governador e temerosos de que não houvesse mais tempo para a aprovação do projeto que tratava da matéria na Assembléia Legislativa, os profissionais resolveram radicalizar o movimento.

Encerrada a greve, veio a resposta do governo no dia seguinte. Embora fosse a suspensão a medida permitida pelo Estatuto dos Funcionários Públicos, o governo achou por bem determinar apenas uma repreensão, justificando que com a suspensão haveria maior prejuízo à população. Também foi constituída uma comissão com três integrantes para apurar os fatos relacionados ao evento, a fim de propor as medidas disciplinares que se entendessem necessárias. Além disso, também se aventaram a existência de perseguições a funcionários, como no caso da direção da Estrada de Ferro Sorocabana, que teria perseguido engenheiros que haviam apoiado ou participado da greve. Contudo, no início de janeiro de 1949, o governo voltou atrás e revogou as sanções. Em sessão da Assembléia Permanente, os profissionais mobilizados comentaram essa medida concluindo que o governador havia percebido que, pelo menos em parte, as suas reivindicações procediam.

Mas os desdobramentos dessa greve não se limitaram a esses fatos. Da parte de médicos e engenheiros, surgiram duas comissões de sindicância, uma de médicos e outra de engenheiros, responsáveis pela apuração da não participação ou oposição de determinados profissionais ao movimento grevista. Tais profissionais poderiam ser excluídos dos quadros de suas respectivas associações e considerados inimigos. No final de março de 1949, a Assembléia Permanente resolveu aprovar a conclusão no sentido da inocência de alguns colegas na sindicância médica, bem como o resultado da sindicância dos engenheiros, que concluíram pela inocência de todos.

A Assembléia Permanente resolveu criar uma outra comissão, sob a liderança do Dr. Alípio, para entender-se com os deputados estaduais a fim de apresentar uma emenda ao projeto de lei n. 209 (Assembléia Permanente de Médicos e Engenheiros, 1949). Este projeto deveria promover um reajustamento de vencimentos e gratificações do funcionalismo estadual, conforme proposta do Executivo em estudo pelos parlamentares desde o primeiro semestre de 1949, e promover a reestruturação de algumas categorias de servidores estaduais. A emenda pretendida pelos médicos e engenheiros deveria equiparar essas categorias aos advogados servidores estaduais.

Este projeto surgiu de uma mensagem do Executivo à Assembléia Legislativa e procurava criar um abono mensal aos quadros do funcionalismo civil em geral, exceto as categorias que percebessem vencimentos acima de oito mil cruzeiros mensais, além de outras categorias determinadas. Contudo, em maio de 1949, o Executivo paulista voltou atrás e retirou a mensagem que originara o projeto. De tal solicitação, no entanto, o governo desistiu logo em seguida e, dias depois, o projeto já estava de volta ao legislativo para apreciação. Outras alterações foram propostas em discussões naquela legislatura, em formato de substitutivo, apresentando possibilidades alternativas de majoração dos vencimentos do funcionalismo estadual. Este projeto atingia um considerável número de servidores, os quais, por intermédio de suas entidades de classe e de contatos com deputados, procuravam influenciar o andamento dos trabalhos e obter o resultado mais favorável aos seus interesses. Contudo, o governo Adhemar percebeu que tais aumentos atingiriam as contas públicas e, a depender de como o projeto fosse aprovado, aventava-se a possibilidade de aumentar os impostos.

Em julho de 1949, o projeto de lei n. 209 já trazia a alteração almejada por médicos e engenheiros. Não por acaso, este acontecimento leva o presidente da APM, Dr. Silvio Lemos do Amaral, a se manifestar em agradecimento junto ao presidente da Assembléia Legislativa e ao deputado Sales Filho, responsável pelo parecer favorável ao projeto.

Em agosto de 1949, os médicos decidiram reforçar a mobilização em âmbito estadual, de tal modo que aceitaram por unanimidade a proposta do Dr. José Salvador Julianelli, o qual, em reunião da Assembléia Permanente, sugeriu que se oficiasse às 13 Assembléias Permanentes do interior do Estado informando sobre a situação da campanha e que se realizassem sessões conjuntas das assembleias do interior e da capital. No entanto, apesar desses esforços, o andamento dos trabalhos na Assembléia Legislativa Estadual não estava muito animador. O projeto de lei estava se arrastando e prometendo demorar até ser aprovado, possuindo àquela altura diferentes tabelas de majoração, as quais tornavam o trabalho de aprovação mais demorado. Diante disso, os profissionais mobilizados decidiram adotar uma postura mais dura em relação aos parlamentares que se mostrassem reticentes ou avessos à mudança legal. Assim, decidiram: acompanhar in loco a discussão/votação do projeto; verificar quais deputados votariam a favor e quais contra, de forma a iniciar uma campanha contrária nas eleições seguintes aos políticos que se mostrassem contrários à aprovação; e, enfim, comprometiam-se a não prestar serviços profissionais aos deputados que negassem a medida legal.

Tal radicalização do movimento gerou protestos de deputados, como foi o caso do deputado Nelson Fernandes. Em discurso na Assembléia Legislativa em outubro daquele ano, este concluiu que o movimento pela equiparação era pilhérico e pilhérica era a decisão dos profissionais de combater os deputados contrários à mudança. $\mathrm{O}$ deputado acusou os dirigentes do movimento de estarem criando uma espécie de circo mais para alavancarem suas posições de dirigentes profissionais do que para trabalharem efetivamente em benefício das carreiras colimadas. 
Os desentendimentos entre médicos e engenheiros, de um lado, e deputados, de outro, levou a uma intervenção externa do arcebispo de São Paulo, D. Carlos Carmelo de Vasconcelos Mota. No Palácio Pio XII, em São Paulo, o arcebispo reuniu líderes dos dois lados. Nessa reunião, não se discutiram particularidades do polêmico projeto, mas acertaram-se as desavenças entre as duas assembléias. Os críticos do movimento ainda assim apontaram restrições à referida reunião; no entanto, o objetivo maior foi alcançado, conseguindo-se trazer calma aos ânimos e a relativa abertura ao diálogo.

Depois de superada essa crise, as atenções concentraram-se na tramitação do projeto de lei n. 209. Embora tivessem tido um parecer desfavorável à medida de equiparação em uma das rodadas de discussão na Comissão de Finanças e Orçamento, até a votação final em plenário os profissionais conseguiram modificar o projeto e reinserir novamente essa medida no corpo do mesmo, sendo este votado e aprovado em votação plenária. A Assembléia Legislativa aprovou o projeto com a reestruturação equiparando médicos e engenheiros aos advogados servidores estaduais. Assim, em um primeiro momento, os médicos obtiveram sucesso em seu trabalho de convencimento junto aos deputados estaduais. Entretanto, o projeto precisava ser aprovado e sancionado pelo governador. Mas este demonstrou uma opinião diferente dos parlamentares paulistas.

Adhemar emitiu um veto parcial ao projeto, desaprovando a medida de equiparação de médicos e engenheiros. Em 10 de janeiro de 1950, foi publicado no Diário Oficial o veto parcial do governador ao projeto, que se baseou em uma justificativa anexa de que somente um aumento na arrecadação de impostos poderia sustentar o gasto público acrescido pela aprovação de medidas de reestruturação de categorias especiais (promulgada Tabela Intermediária do Projeto 209, 1950). Enfim, em 24 de novembro de 1950, os deputados estaduais decidiram aceitar o veto do governador, encerrando de uma vez por todas a questão de equiparação.

\section{Considerações Finais}

Em todo esse percurso, os médicos paulistas empenharam-se fortemente numa estratégia de ação que, em determinados momentos, tornou rarefeitas as fronteiras entre política convencional e profissionalismo. Partindo de uma demanda sustentada na questão do tratamento desigual às carreiras de Nivel Superior por parte do governo estadual, bem como de um relativo entendimento com o Executivo paulista, os médicos atingiram o ponto de considerar o governador Adhemar de Barros um inimigo da profissão; por outro lado, o mesmo se deu quanto à relação dos médicos com a Assembléia Legislativa, situação contornada apenas através de uma intervenção externa do arcebispo de São Paulo. Os médicos politizaram sua ação enquanto grupo de tal maneira que contrariaram um princípio básico da profissão médica e afirmaram publicamente que não prestariam seus serviços profissionais aos deputados que fossem contrários à medida de equiparação, ou seja, afirmaram que iriam sobrepor um interesse de cunho econômico-político ao princípio de neutralidade ético-profissional.

Por outro lado, os médicos mobilizados realizaram uma sindicância contra colegas não favoráveis à tática grevista, demonstrando como os critérios da política convencional haviam permeado profundamente sua ação como grupo. Assim, entre os médicos da Assembléia Permanente, predominou a política convencional sobre elementos importantes do profissionalismo. É bem verdade que seria difícil imaginar uma postura muito diferente quanto a um movimento claramente de natureza política, o qual reivindicava uma mudança de tipo legal, mas com desdobramentos socioeconômicos. Com efeito, podemos dizer que, como nos lembra Halliday (1999), os médicos do Estado experimentaram toda a carga contraditória da ação política de um grupo profissional que se propõe a defender uma causa e vencer na arena da política convencional.

Nesse caminho, os médicos mobilizados conseguiram espaço na imprensa e no meio político, obtiveram o apoio de importantes instituições e associações profissionais, tornaram a Assembléia Permanente um fenômeno sociopolítico que atingiu os médicos tanto da capital como do interior paulista, formando núcleos em vários centros interioranos, além de terem defendido uma causa que sensibilizou diferentes grupos médicos, atravessando diferenças internas à medicina daquele tempo - mesmo que se possa afirmar que esse movimento não tenha mobilizado a totalidade do grupo médico paulista e que suas táticas de ação possam ter contrariado interesses, valores e ideias de determinados segmentos médicos.

Isso posto, embora seja possível afirmar que as ações recíprocas entre os médicos paulistas e o governo Adhemar se caracterizaram por momentos de aproximação e momentos de distanciamento, e até conflito, com a convivência de posições contraditórias e ambivalentes, acreditamos que tenha ficado explícita a capacidade de mobilização coletiva dos médicos paulistas do período analisado e como predominou a coesão interna do grupo profissional ante a política adhemarista, mobilizando inclusive associações e organizações médicas com origens, perfis e composição diferenciadas. Assim, se o movimento de Assembléia Permanente evidenciou como ainda não estavam claramente estabelecidas as fronteiras entre profissionalismo e política - que representa uma das bases da autonomia profissional -, também é verdade que o movimento favoreceu o grupo médico paulista por meio de sua capacidade de mobilização associativa, a qual também é importante para o fortalecimento e manutenção do poder ou autonomia profissional.

Na realidade, embora esta mobilização tenha favorecido os médicos do ponto de vista de sua autonomia, por meio do crescimento de sua capacidade coletiva de 
organização, eles não conseguiram ultrapassar o limite representado pelo poder de influência que a esfera política do Estado controla. Apesar de todo o trabalho político de convencimento, tanto do Legislativo como do Executivo estaduais, os médicos não conseguiram aprovar a medida legal que tanto desejavam.

\title{
Referências
}

DUARTE, Adriano Luiz. Cultura popular e cultura política no após-guerra: redemocratização, populismo e desenvolvimentismo no Bairro da Mooca - 1942-1973. Tese (Doutoramento em História) - IFCH, UNICAMP, Campinas, 2002.

FARIA, Lina Rodrigues de; SANTOS, Luiz Antônio de Castro. Os primeiros centros de saúde nos Estados Unidos e no Brasil: um estudo comparativo. Teoria e pesquisa, São Carlos, n. 40-41, p. 137-181, jan./jul. 2002.

FREIDSON, Eliot. Professionalism: the third logic. Cambridge: Polity Press, 2001.

FREIDSON, Eliot. Profissão médica: um estudo de sociologia do conhecimento aplicado. São Paulo: Edunesp, 2009. FRENCH, John. O ABC dos operários: conflitos e alianças de classe em São Paulo: 1900-1950. São Paulo: Hucitec, 1995. HALLIDAY, Terence C. Politics and civic professionalism: legal elites and cause lawyers. Law and Social Inquiry, n. 24, p. 1013-1060, 1999.

MÉDICOS DO ESTADO. O Estado de São Paulo. São Paulo, 27 mai. 1948.

MÉDICOS E ENGENHEIROS. O Estado de São Paulo. São Paulo, 17 out. 1948

ORTIZ, Renato (Org.). Pierre Bourdieu: sociologia. São Paulo: Ática, 1983.

RAMOS, Jairo. Considerações sobre a socialização da profissão médica no Brasil. Revista Paulista de Medicina, São Paulo, v. XXXV, n. 4, p. 71, out. 1949.

\section{Cohesion and interests of the São Paulo's medicine ahead of adhemarista populism: contradictions and ambivalences}

\begin{abstract}
This article investigates the relationship between the professionalization process of São Paulo's doctors and the adhemarismo phenomenon. As governor, Adhemar de Barros developed health politics which have interfered in the professionalization process of this occupation in São Paulo. We evaluate how this occupation related with the adhemarismo State, emphasizing the politic-professional interests and the associative actions in terms of approximation-detachment between doctors and the State. Our focus is directed to his second government (1947-1951) when occurred the movement of "Assembléia Permanente de Médicos e Engenheiros". Doctors and engineers sought their economic and juridical equalization, such as public careers, along with lawyers, in a move that revealed the contradictions and ambivalences between professionalism and political, as well as the cohesion of the medical association and how the boundaries between professionalism and political were not well demarcated between these doctors.
\end{abstract}

Keywords: São Paulo’s medicine; adhemarismo; professionalism and policy; professional interests.

\section{La cohesión y los intereses de profesionales médicos de São Paulo frente al adhemarismo: contradicciones $\gamma$ ambivalencias}

\footnotetext{
Resumen

Este artículo trata de la relación entre el proceso de profesionalización de los médicos y el fenómeno de adhemarismo. Como gobernador, Adhemar de Barros produjo políticas de salud que interferirán en el proceso de profesionalización en la carrera en São Paulo. Estudiamos cómo la profesión se relaciona con el estado, enfocando las acciones políticas y los intereses profesionales de acercamiento y alejamiento entre los médicos y el gobierno. Nuestro planteamiento está orientado a su segundo gobierno (1947-1951), cuando se produjo el movimiento de Assembléia Permanente de Médicos e Engenheiros, que trató de equiparar la carrera médica pública con la carrera de los abogados, una medida que revela las contradicciones y ambivalencias entre el profesionalismo y la política, así como la cohesión médica y los límites entre el profesionalismo y la política que no estaban tan claro entre ellos.

Palabra-clave: en São Paulo, adhemarismo, profesionalismo y política de la medicina; intereses profesionales.
} 